\title{
O PAPEL DOS PROGRAMAS INTERLABORATORIAIS PARA A QUALIDADE DOS RESULTADOS ANALÍTICOS
}

\section{Queenie Siu Hang Chui*}

Unidade Acadêmica da Área de Ciências Exatas e Tecnológicas, Universidade São Francisco,

Rua Alexandre Rodrigues Barbosa, 45, 13251-900 Itatiba - SP

João Marcos de Almeida Bispo e Célia Omine Iamashita

Divisão de Química, Instituto de Pesquisas Tecnológicas do Estado de São Paulo S.A.,

Av. Prof. Almeida Prado, 535, 05508-901 São Paulo - SP

Recebido em 16/12/03; aceito em 1/3/04; publicado na web 6/7/2004

\begin{abstract}
INTERLABORATORIAL PROGRAMS FOR IMPROVING THE QUALITY OF ANALYTICAL RESULTS. Interlaboratorial programs are conducted for a number of purposes: to identify problems related to the calibration of instruments, to assess the degree of equivalence of analytical results among several laboratories, to attribute quantity values and its uncertainties in the development of a certified reference material and to verify the performance of laboratories as in proficiency testing, a key quality assurance technique, which is sometimes used in conjunction with accreditation.

Several statistics tools are employed to assess the analytical results of laboratories participating in an intercomparison program. Among them are the z-score technique, the elypse of confidence and the Grubbs and Cochran test.

This work presents the experience in coordinating an intercomparison exercise in order to determine $\mathrm{Ca}, \mathrm{Al}, \mathrm{Fe}, \mathrm{Ti}$ and $\mathrm{Mn}$, as impurities in samples of silicon metal of chemical grade prepared as a candidate for reference material.
\end{abstract}

Keywords: interlaboratorial program; silicon metal of chemical grade; certified reference material.

\section{INTRODUÇÃO}

Muitos se perguntam: por que participar de programas interlaboratoriais? Quais são os benefícios que usufruo participando de programas interlaboratoriais? Enfim, o que são programas interlaboratoriais? E qual é a relação entre programas interlaboratoriais e qualidade de resultados?

A qualidade de um resultado analítico é verificada através da incerteza a ele associada. A média de " $n$ " repetições não é suficiente para expressar o resultado final em ensaios e análises químicas. Ele deve ser expresso associado a sua incerteza que, por sua vez, é definida como um parâmetro associado ao resultado de medição que caracteriza a dispersão dos valores, quando se deve levar em consideração todos os fatores de influências para as variabilidades do processo de medição envolvido ${ }^{1,2}$. Ao mesmo tempo, sua exatidão deve também ser comprovada.

A exatidão de um resultado pode ser comprovada através do emprego de materiais de referência ou, na ausência destes, através dos chamados "métodos primários", ou seja, métodos absolutos que não envolvem padrões analíticos ${ }^{3}$. Porém muitas vezes, os métodos primários também não estão disponíveis. Nesse caso, a participação em programas interlaboratoriais, com vários laboratórios trabalhando com métodos independentes, pode representar a solução mais adequada.

Medições em análises químicas, quer sejam para o controle da qualidade de processos e produtos ou destinadas ao acompanhamento de trabalhos de pesquisa e desenvolvimento, quando consideradas "erradas" ou não suficientemente confiáveis, podem representar grande desperdício de tempo e dinheiro ${ }^{4}$. Para auxiliar os laboratórios na busca de fontes de erros, para eliminá-los ou minimizar seus efeitos, a participação em trabalhos de comparação interlaboratorial pode substituir o controle interno da qualidade laboratorial.

*e-mail: queenie.hang@saofrancisco.edu.br
O planejamento para o desenvolvimento de um programa interlaboratorial visa atingir as finalidades para as quais ele se propõe. Entre as várias finalidades possíveis estão a avaliação da competência técnica de laboratórios (testes de proficiência); a compatibilização de resultados de diversos laboratórios, quando não existem valores de referência a serem atribuídos à propriedade desejada; o estudo para determinação de parâmetros de precisão de metodologias e seu emprego como ferramenta importante em trabalhos envolvendo a certificação de materiais de referência ${ }^{5}$.

\section{FERRAMENTAS ESTATÍSTICAS PARA PROGRAMAS INTERLABORATORIAIS}

Várias são as técnicas estatísticas empregadas para a avaliação de resultados em programas interlaboratoriais. Este trabalho descreve aquelas que estão sendo mais utilizadas nos programas para a qualidade analítica.

\section{Técnica do z-score}

A técnica de z-score ${ }^{6-8}$ é adotada quando se deseja avaliar o desempenho técnico de laboratórios, principalmente em testes de proficiência. O conceito da estatística "z" da distribuição normal é a base matemática desta técnica. $\mathrm{O}$ valor de " $\mathrm{z}$ ", para cada laboratório, é obtido calculando a expressão $\mathrm{z}=(\mathrm{x}-\mu) / \sigma$; " $\mathrm{x}$ " é o valor do resultado obtido pelo laboratório participante, " $\mu$ " é a estimativa do valor verdadeiro e " $\sigma$ " é a estimativa do desvio padrão para " $\mu$ ".

Valores de z-score são valores padronizados que atribuem uma nota relativa aos demais no grupo para cada resultado. $\mathrm{O}$ gráfico de barras mostrado na Figura 1 representa valores obtidos por laboratórios ordenados conforme seu desempenho.

$\mathrm{O}$ valor z-score de cada laboratório é apresentado no gráfico e identificado pelo seu número código, que é usado para manter de modo confidencial a identidade do laboratório. Os limites de \pm 3 z-score 


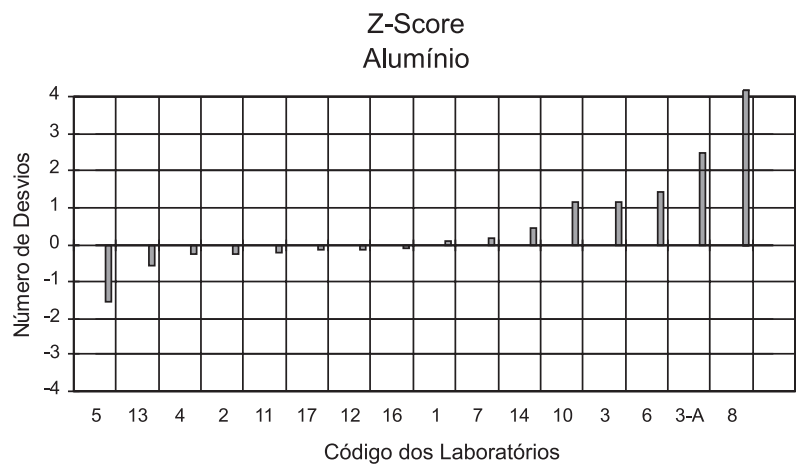

Figura 1. Gráfico típico de valores de z-score para avaliação de desempenho de laboratórios em programas interlaboratoriais

também são mostrados, de forma a facilitar a identificação das barras que ultrapassam esses limites e que, neste caso, serão considerados resultados de laboratórios dispersos.

A aceitação de desempenho do laboratório segue o seguinte critério: $|\mathrm{z}| \leq 2$ indica desempenho satisfatório; se $2<|\mathrm{z}|<3$, o desempenho é questionável; e quando $|\mathrm{z}| \geq 3$ o desempenho é considerado não satisfatório.

Em situações em que o valor considerado como "verdadeiro" não existir, para o cálculo da estimativa de " $\mu$ " poderá ser considerado o valor da média do conjunto de laboratórios", excluídos os valores dispersos após a aplicação de testes de rejeição de Cochran e de Grubbs $^{10}$. Porém, mesmo aplicados os testes para os dispersos, dependendo dos graus de liberdade envolvidos (no caso específico, número de laboratórios participantes), a estimativa da média poderá estar afetada pelos valores extremos. Nesse caso são utilizadas a mediana (md) e o intervalo interquartílico normalizado ${ }^{11-13}$.

A abordagem do z-score robusto ${ }^{14}$ tem sido recomendada pela NATA-Austrália "National Association for Testing Authorities", país pioneiro em Sistemas da Qualidade. Com a mediana (md), a estimativa de " $\mu$ " não é afetada pelos valores extremos. E, ao invés de desvio padrão, é empregada a amplitude interquartílica (IQ), que é a diferença entre o maior quartil (Q3) e o menor quartil (Q1). Q1 é o valor abaixo do qual estão presentes $25 \%$ dos resultados. Analogamente, Q3 é o valor acima do qual estão presentes outros $25 \%$ dos resultados.

O valor da amplitude interquartílica normalizada (IQN) é expresso como 0,7413 do valor da amplitude interquartílica, ou seja, IQN = IQ · 0,7413. O fator 0,7413 vem da distribuição normal padrão. Multiplicar a amplitude interquartílica por este fator, torna-o comparável ao desvio padrão.

Na prática, é usual avaliar o valor de z-score robusto entre laboratórios e dentre laboratórios. O cálculo do "z-score" depende do planejamento estatístico do programa. Na maioria dos casos os programas são planejados de modo que pares de resultados sejam obtidos, isto é, duas amostras sejam distribuídas, ou (menos freqüentemente e evitado se possível) dois resultados para a mesma amostra sejam requeridos. Pares de resultados são necessários para avaliar ambas as fontes de variação: a variabilidade dentre laboratórios e a variabilidade entre laboratórios.

Para cada par de resultados, dois valores de "z-score" são calculados. O "z-score entre laboratórios" será baseado na soma dos resultados do par, enquanto que o "z-score dentro do laboratório" será baseado na diferença dos resultados do par. Para o cálculo dos valores robustos de "z-score" são utilizadas a mediana (md) e a amplitude interquartílica normalizada (IQN), ao invés da média e do desvio padrão.

$\mathrm{O}$ z-score entre laboratórios é baseado na soma padronizada $\mathrm{S}=$ $(\mathrm{A}+\mathrm{B}) / \sqrt{2}$ do par de resultados relatados pelo laboratório. $\mathrm{O}$ valor de
Z-score entre laboratórios é calculado como:

z score entre laboratórios $=\frac{S-\operatorname{md}(S)}{\operatorname{IQN}(S)}$

$\mathrm{O}$ z-score dentre laboratórios é baseado na diferença padronizada $D=(A-B) / \sqrt{ } 2$ se a mediana $(A)$ for maior que a mediana $(B)$ ou (B-A) $/ \sqrt{ } 2$ se a mediana (A) for menor que a mediana (B), do par de resultados relatados pelo laboratório. $\mathrm{O}$ valor de $\mathrm{z}$-score dentro do laboratório é calculado como:

z score dentro do laboratório $=\frac{\mathrm{D}-\mathrm{md}(\mathrm{D})}{\mathrm{IQN}(\mathrm{D})}$

O programa computacional utilizado pode ser planejado para apresentar apenas um simples resultado em uma simples amostra (C).

z score $=\frac{C-\operatorname{md}(C)}{I Q N(C)}$

Nesse caso, não se distinguem as variabilidades entre e dentre laboratórios.

Valor de z-score entre laboratórios muito alto indica que um ou ambos os resultados do laboratório são significativamente maiores que o valor de consenso (mediana). De modo similar, se o valor de zscore entre laboratórios é muito baixo (negativo) há indicação de que um ou ambos os resultados do laboratório são significativamente menores que o valor de consenso.

Por sua vez, valor de z-score dentro do laboratório muito alto (positivo) ou muito baixo (negativo) indica que a diferença entre os resultados do laboratório é muito grande ou muito pequena, respectivamente.

Gráficos de barras, como o apresentado na Figura 1, ordenando valores de z-score entre laboratórios e valores de z-score dentro do laboratório são também utilizados para ilustrar os resultados.

No caso de o programa prever apenas um simples resultado em uma simples amostra, apenas o valor de z-score entre laboratórios é calculado.

A aceitação de desempenho do laboratório segue o mesmo critério descrito anteriormente, quando se procede à avaliação pelo zscore tradicional.

\section{Técnica da elipse de confiança}

A técnica do gráfico da elipse de confiança é mais utilizada para verificar a compatibilidade entre os laboratórios, e segue o método de Youden ${ }^{15-17}$. O planejamento experimental para a construção da elipse de confiança prevê a distribuição de um par de amostras semelhantes, não necessariamente de concentrações iguais, porém de concentrações próximas. A elipse é construída para cada ensaio e cada laboratório é representado por um ponto. As retas que passam pelas médias dos laboratórios, em $x$ (resultados relativos à uma das amostras analisadas) e em $y$ (resultados relativos a outra amostra analisada), dividem o diagrama em quadrantes. Pontos encontrados nos quadrantes superior direito e inferior esquerdo representam laboratórios que podem estar incorrendo em erros sistemáticos. Na prática, quando somente erros aleatórios estão presentes, os pontos devem estar distribuídos de modo uniforme em todos os quadrantes. Se os pontos se encontrarem mais concentrados nos quadrantes superior direito e inferior esquerdo, isto é interpretado como evidência de ocorrência de erros sistemáticos, ou seja, os laboratórios tendem a obter valores altos ou baixos, em ambas as amostras do par. 
A elipse de confiança é traçada de tal modo que qualquer ponto tem a mesma probabilidade de estar dentro da elipse e, em geral, é estabelecido o grau de $95 \%$ de confiança. Geralmente os pontos se situam dentro de uma elipse, cujo eixo maior faz um ângulo de aproximadamente $45^{\circ}$ com o eixo da horizontal. Portanto a inclinação maior da elipse está próxima de +1 e a do eixo menor, de -1 . A dispersão dos pontos ao longo do eixo maior está associada aos erros sistemáticos, enquanto que ao longo do eixo menor está associada aos erros aleatórios.

Erros sistemáticos e aleatórios:

Os valores $x_{i}$ e $y_{i}$ obtidos em medição, diferem dos valores verdadeiros $\alpha$ e $\beta$ para as amostras A e B. Essa diferença, ou "erro", é composta de duas parcelas:

$\mathrm{x}_{\mathrm{i}}-\alpha=\mathrm{L}_{\mathrm{i} \alpha}+\mathrm{R}_{\mathrm{i}}$

$\mathrm{y}_{\mathrm{i}}-\beta=\mathrm{L}_{\mathrm{i} \beta}+\mathrm{R}_{\mathrm{i}}$

onde $\mathrm{L}_{\mathrm{i}}=$ erros sistemáticos e $\mathrm{R}_{\mathrm{i}}=$ erros aleatórios

Como geralmente são desconhecidos os valores verdadeiros de $\alpha \mathrm{e}$ $\beta$, estes são substituídos pelas estimativas $\overline{\mathrm{x}}$ e $\overline{\mathrm{y}}$ e $R_{i A}$ e $R_{i B}$.

$x_{i}-\bar{x}=L_{i \alpha}+R_{i A}$

$y_{i}-\bar{y}=L_{i \beta}+R_{i B}$

ou

$X_{i}=L_{i \alpha}+R_{i A}$

$Y_{i}=L_{i \beta}+R_{i B}$

A interpretação dos resultados de programas interlaboratoriais, utilizando a técnica da elipse de confiança para compatibilização de resultados, é feita através da análise dos erros aleatórios e sistemáticos, associando-os aos eixos da elipse de confiança e à inclinação do seu eixo maior com relação ao eixo das abcissas.

Esta associação pelo método dos componentes principais foi estabelecida ${ }^{18}$ através das etapas:

I. Cálculo de:

$S^{2}=\Sigma X^{2}$

$S_{y}^{2}=\Sigma Y_{i}^{2}$

$S_{x y}^{y}=\Sigma X_{i}^{i} Y_{i}$

onde $\mathrm{S}_{\mathrm{x}}^{2}$ é a soma quadrática das diferenças de $\mathrm{x} ; \mathrm{S}_{\mathrm{y}}^{2}$ é a soma quadrática das diferenças de y e $\mathrm{S}_{\mathrm{xy}}$ é a soma do produto das diferenças de $\mathrm{x}$ e $\mathrm{y}$.

II. Resolução de:

$\lambda^{2}-\left(S_{x}^{2}+S_{y}^{2}\right) \cdot \lambda+\left(S_{x}^{2} \cdot S_{y}^{2}-S_{x y}\right)=0$

Esta equação fornece dois valores positivos de $\lambda_{1}$ e $\lambda_{2}$, sendo $\lambda_{1}$ $>\lambda_{2}$. Estes valores representam a soma dos quadrados das projeções dos pontos do diagrama de dispersão sobre os eixos maior e menor da elipse de confiança, respectivamente.

III. Cálculo do ângulo:

$\operatorname{tg} \gamma=\frac{\left(\lambda_{1}-S_{x}^{2}\right)}{S_{x y}} \geq 0$
Esta equação fornece o ângulo “ $\gamma$ " formado entre o eixo maior da elipse $\left(\lambda_{1}\right)$ e o eixo das abcissas.

Considerando que numericamente as propriedades do par de amostras são próximas, pode-se considerar as seguintes condições: a) os valores médios $\bar{x}$ e $\bar{y}$ são aproximadamente iguais; b) os erros sistemáticos para um dado laboratório são iguais para as duas amostras e c) os erros aleatórios podem ser iguais ou diferentes para as duas amostras.

No caso em que os erros aleatórios podem ser considerados iguais, a elipse estará posicionada no gráfico com seu eixo maior a $45^{\circ} \mathrm{em}$ relação ao eixo das abcissas. A dispersão em torno do eixo menor da elipse representa apenas os erros aleatórios, enquanto que a dispersão ao longo do eixo maior representa os erros sistemáticos. A representação gráfica está na Figura 2.

Quando os erros aleatórios são ambos pequenos, mas não necessariamente iguais em relação aos erros sistemáticos, a elipse de confiança apresentar-se-á orientada com seu eixo maior a aproximadamente $45^{\circ}$, em relação ao eixo das abcissas, porém com uma forma mais alongada. A representação gráfica está na Figura 3.

Se os erros aleatórios das duas amostras forem bem diferentes, e o erro sistemático de uma delas se aproximar do erro aleatório, a elipse de confiança poderá ter seu eixo maior entre $30^{\circ}$ e $90^{\circ}$, em relação ao eixo das abcissas. A representação gráfica está na Figura 4.

Dependendo dos valores atribuídos aos erros sistemáticos e aos erros aleatórios, o eixo maior pode até apresentar-se na horizontal, ou seja, a $0^{\circ}$ com relação ao eixo das abcissas. Se o erro sistemático é muito pequeno em relação ao aleatório, os eixos da elipse tendem a um mesmo valor e a região de confiança aproxima-se de um círculo. A representação gráfica está na Figura 5.

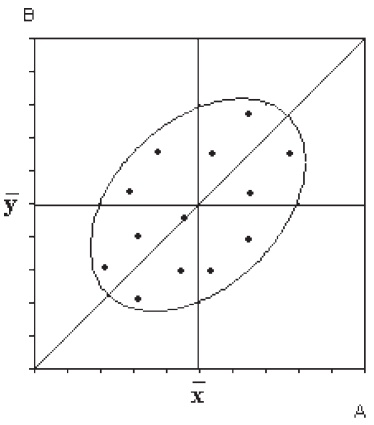

(a)

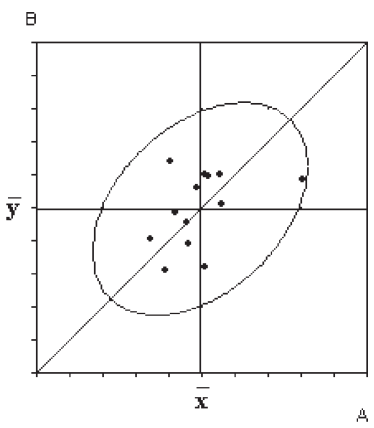

(b)
Figura 2. Elipse de confiança com seu eixo maior a $45^{\circ}$ em relação ao eixo das abcissas: (a) dispersão uniforme, (b) dispersão não uniforme

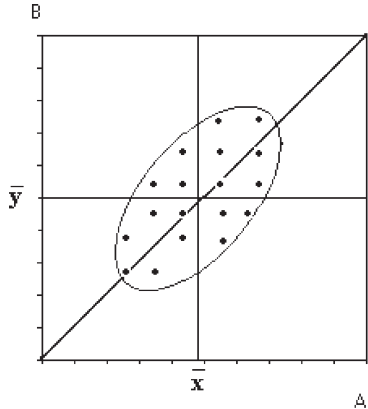

(a)

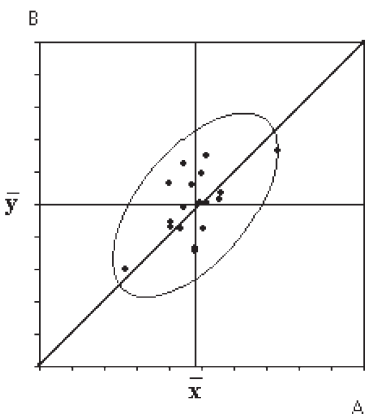

(b)
Figura 3. Elipse de confiança com o eixo maior a aproximadamente $45^{\circ}$ com relação ao eixo das abcissas e forma alongada. (a) dispersão uniforme (b) dispersão não uniforme 


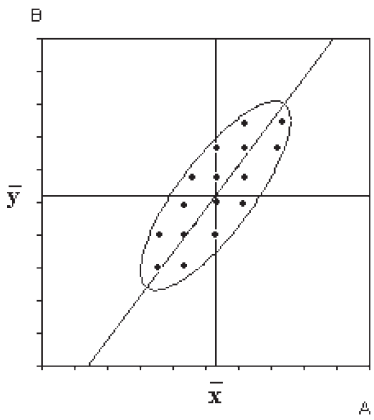

(a)

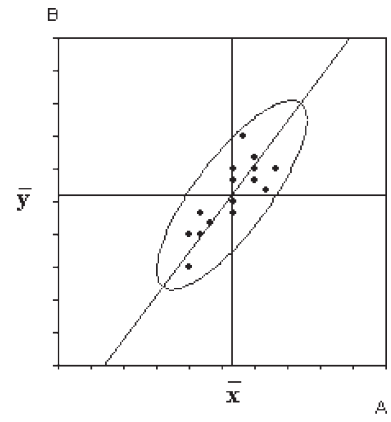

(b)
Figura 4. Elipse de confiança com seu eixo maior entre $30^{\circ}$ e $90^{\circ}$ em relação ao eixo das abcissas. (a) dispersão uniforme (b) dispersão não uniforme

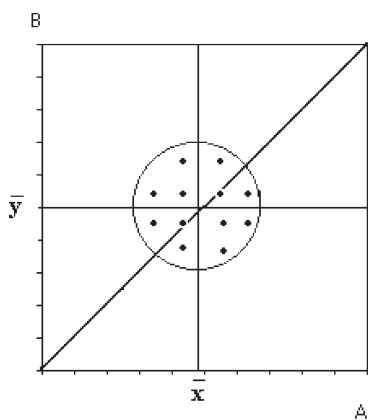

(a)

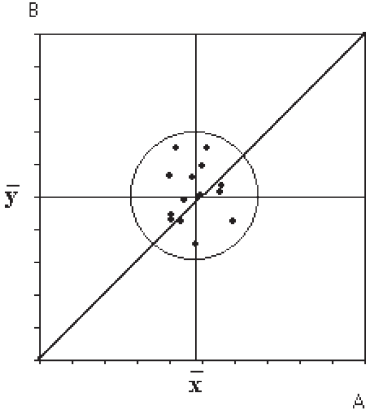

(b)
Figura 5. Elipse de confiança: (a) dispersão uniforme (b) dispersão não uniforme

O desenvolvimento de programas computacionais para elipse de confiança segue a equação abaixo ${ }^{19}$ :

$T_{\varepsilon}=\frac{\left(x_{i}-\bar{x}\right)^{2} \cdot \sigma_{y}^{2}-2\left(x_{i}-\bar{x}\right) \cdot\left(y_{i}-\bar{y}\right) \cdot \sigma_{x y}+\left(y_{i}-\bar{y}\right)^{2} \cdot \sigma_{x}^{2}}{\sigma_{x}^{2} \cdot \sigma_{y}^{2}-\sigma_{x y}}$

$\varepsilon=$ nível de significância; $\mathrm{T}$ e $\varepsilon$ estão relacionados pela expressão $\varepsilon=1-\mathrm{e}^{(-\mathrm{T} \varepsilon / 2)} ; \overline{\mathrm{x}}=$ média dos resultados para a amostra $\mathrm{A} ; \overline{\mathrm{y}}=$ média dos resultados para a amostra $\mathrm{B} ; \sigma_{\mathrm{x}}^{2}=$ variância dos resultados da amostra $\mathrm{A} ; \sigma_{\mathrm{y}}^{2}=$ variância dos resultados da amostra $\mathrm{B}$ e $\sigma_{\mathrm{xy}}=$ covariância dos resultados das amostras A e B.

O Programa Computacional desenvolvido considera o cálculo da elipse com $95 \%$ de confiança para a eliminação de pontos dispersos e, logo em seguida, nesse mesmo nível de confiança, a construção da elipse final.

Pontos fora da elipse representam os laboratórios que não apresentam resultados compatíveis com os dos demais. Aos laboratórios posicionados dentro da elipse, porém muito distantes dos demais, também deve ser dada a devida atenção, procurando-se detectar os possíveis problemas que os estão levando à maior dispersão.

\section{Testes de Cochran e Grubbs}

São testes estatísticos geralmente utilizados para a análise de resultados dispersos, antes de se proceder à interpretação de resultados populacionais de distribuição normal.

O teste de Cochran é aplicado quando se deseja comparar variâncias, ou seja, verificar se a variância dos resultados obtidos por um laboratório é diferente da variância dos demais laboratórios. É um teste unilateral, pois verifica somente valores altos. Calculam- se as variâncias dos resultados de cada laboratório e, em seguida, somam-se todas as variâncias. Obtém-se o valor para o coeficiente de Cochran ${ }^{9}$, relacionando-se a maior variância com o valor resultante da soma de variâncias. Através da comparação do valor calculado com valores de tabela em nível de confiança pré-estabelecido, toma-se a decisão se o valor é aceito ou rejeitado como disperso.

O teste de Grubbs verifica se as médias obtidas pelos vários laboratórios são compatíveis, após efetuado o teste de Cochran. A diferença entre o valor julgado suspeito e o valor da média dos laboratórios é relacionado com o desvio padrão do mesmo conjunto de laboratórios. O valor resultante dessa relação é comparado com valores tabelados ${ }^{10}$.

\section{Técnica da análise das variâncias}

A análise de variâncias (ANAVA) é usada para analisar observações que dependem de um ou mais efeitos, que são causados por fatores, cujos níveis também são denominados grupos; no caso específico, laboratórios diferentes.

A ANAVA-fator único é um dos modelos estatísticos recomendados, quando os resultados de um programa interlaboratorial são utilizados para estudar o efeito devido à variabilidade de laboratórios. A influência de operadores, equipamentos, métodos e amostras sobre os resultados obtidos pelos laboratórios pode ser estudada usando a análise de variância fator duplo ou múltiplo.

Em trabalhos de certificação de materiais de referência, se se aplica ANAVA-fator duplo é possível, ao mesmo tempo, confirmar a homogeneidade do lote preparado. A média como o valor de consenso, as variâncias entre laboratórios, dentre laboratórios e entre frascos são estimadas simultaneamente. São necessárias as determinações de mesmo número de replicatas em cada frasco e mesmo número de frascos para cada laboratório participante. Detalhes teóricos são apresentados em livros textos ${ }^{20,21}$ e nas instruções da norma ISO $35^{22}$ e não serão discutidos neste trabalho.

\section{Índices de repetitividade e reprodutibilidade}

Usando a análise pelas variâncias, em programa interlaboratorial, é possível a determinação de parâmetros de precisão para métodos de ensaios ${ }^{10}$. Muitas normas brasileiras ainda não incluem informações a respeito desses parâmetros. Resultados de ensaios, mesmo obtidos com métodos normalizados, apresentam variabilidades. $\mathrm{Na}$ interpretação de resultados de ensaios, as variabilidades intrínsicas e extrínsicas referentes aos laboratórios participantes do programa interlaboratorial são consideradas.

Dois parâmetros de precisão ${ }^{23}$, os denominados índices de repetitividade - Repê (r) e reprodutibilidade - Reprô ( $R$ ), têm demonstrado serem necessários e suficientes para descrever as variabilidades de um método de ensaio ${ }^{10,24-26}$. O índice " $r$ " indica a diferença máxima aceitável entre pelo menos dois resultados. Esses resultados referemse a medidas obtidas em medições "quase iguais", dentro de um mesmo laboratório. Por sua vez, "R" indica a diferença máxima aceitável entre pelo menos dois resultados de laboratórios diferentes. $\mathrm{O}$ valor dos índices é determinado a partir da média dos erros internos de todos os laboratórios, e só tem validade para uso por laboratórios que participaram do programa interlaboratorial planejado para este fim.

Aplicados os testes de Cochran e de Grubbs ${ }^{10}$ para rejeição dos dispersos, as variâncias entre $\left(\mathrm{sb}^{2}\right)$ e dentre $\left(\mathrm{sw}^{2}\right)$ laboratórios ${ }^{24}$ são calculadas através da ANAVA-fator único. Considerando que $\mathrm{sb}^{2}=$ $\mathrm{sw}^{2}+\mathrm{n} \mathrm{s}^{2}$, sendo " $\mathrm{s}$ " " a parcela de variabilidade devido a laboratórios e "n", o número de replicatas analisadas por laboratório, calcula-se:

$r($ repê $)=2,77$ sw e $R($ Reprô $)=2,77\left(s^{2}+s^{2}\right)^{1 / 2}$ 
Os índices "r" e "R" são obtidos associando-se aos valores das variâncias coeficientes que levam em consideração o grau de confiança desejado. Com um grau de confiança de $95 \%$, o coeficiente é igual a 2,77 válido para a diferença máxima permitida entre 2 resul$\operatorname{tados}^{24-26}$.

A repê (r) e a Reprô (R) devem ser mantidas sob controle, entendendo-se por "sob controle" a estabilidade, ao longo do tempo, para um determinado processo metrológico.

Os valores de r e R têm aplicação direta no dia a dia do laboratório, após o mesmo participar do programa interlaboratorial do qual os mesmos foram obtidos; são aplicados para as questões internas do controle de produção em indústrias, para o controle da qualidade de resultados de ensaios em laboratórios e em situações de impasse envolvendo a relação fornecedor-comprador, quando se tem de decidir sobre aceitação ou rejeição de bens e serviços ${ }^{23}$.

Vale salientar que os índices $\mathrm{r}$ e R são dinâmicos e devem ser reavaliados com certa frequiência, através de nova rodada dos trabalhos de comparação interlaboratorial.

\section{OBJETIVO}

O presente trabalho apresenta a experiência em utilizar programas interlaboratoriais para determinação de contaminantes $(\mathrm{Ca}, \mathrm{Al}$, $\mathrm{Fe}$, Ti e Mn) presentes em amostras de silício metálico grau químico candidato a material de referência.

\section{METODOLOGIA}

Dois pequenos lotes de material silício de aproximadamente $5 \mathrm{~kg}$ cada foram preparados nas instalações do Laboratório de Materiais de Referência Inorgânicos (LMRI) da Divisão de Química do IPT. Os materiais foram recebidos com tamanho de partículas $<10 \mathrm{~mm}$, provenientes da empresa Ligas de Alumínio S.A., MG, sendo moídos e peneirados em malha de 100 mesh ABNT, obtendo-se partículas menores que $150 \mu \mathrm{m}$. Com essa operação, resultaram 50 frascos por lote, cada frasco contendo aproximadamente $80 \mathrm{~g}$ de amostra de silício.

$\mathrm{O}$ número de frascos $\operatorname{amostrados}^{27}$ foi de $3 \times \mathrm{N}^{1 / 3}$, ou seja, 11 frascos. A técnica analítica empregada para as determinações de elementos foi a espectrometria de plasma de argônio indutivamente acoplado (ICP-OES Spectroanalytical Instruments), após uma alíquota da amostra (cerca de $1 \mathrm{~g}$ ) ser digerida com $\mathrm{HNO}_{3}$ concentrado $(20 \mathrm{~mL})$ e HF $(10 \mathrm{~mL}$, gota a gota) até a dissolução total. Diluições suficientes foram feitas para atender à faixa linear de trabalho de cada um dos elementos. As condições operacionais do espectrômetro, para cada elemento, seguiram as estabelecidas na rotina de trabalho do LMRI.
Os resultados obtidos para média e desvio padrão, para os elementos analisados, de 7 replicatas realizadas para cada frasco foram $(340 \pm 20) \mathrm{mg} / \mathrm{kg}$ de $\mathrm{Ca},(580 \pm 20) \mathrm{mg} / \mathrm{kg}$ de Al, $(75 \pm 2) \mathrm{mg} / \mathrm{kg} \mathrm{de}$ $\mathrm{Ti},(2800 \pm 100) \mathrm{mg} / \mathrm{kg}$ de Fe para o lote denominado A e (450 \pm 10$)$ $\mathrm{mg} / \mathrm{kg}$ de Ca, $(640 \pm 30) \mathrm{mg} / \mathrm{kg}$ de Al, $(63 \pm 3) \mathrm{mg} / \mathrm{kg}$ de Ti, $(2700 \pm$ 200) $\mathrm{mg} / \mathrm{kg}$ de Fe para o lote denominado B.

Para o exercício de comparação interlaboratorial, foram distribuídas duas amostras (uma de cada lote) a 12 laboratórios participantes. Foi permitido que os laboratórios adotassem seu método de rotina para a determinação de $\mathrm{Ca}, \mathrm{Fe}, \mathrm{Al}, \mathrm{Mn}$ e Ti, que abrangeu a fluorescência de Raios X (FRX), a espectrometria de emissão por plasma de argônio (ICP-OES) e a espectrometria de absorção atômica com chama (AA).

Para verificar a rastreabilidade dos resultados, sugeriu-se que os laboratórios participantes utilizassem referências comercialmente disponíveis ou outro material de matriz similar, bem caracterizado, contendo a composição conhecida dos elementos de interesse.

Os resultados obtidos pelos laboratórios foram estatisticamente avaliados, usando a técnica da elipse de confiança com $95 \%$ de confiança, a do z-score robusto e os testes de Cochran e de Grubbs, para a análise dos dispersos. Índices de repetitividade e reprodutibilidade foram calculados, usando a análise pelas variâncias.

\section{RESULTADOS E DISCUSSÃO}

A primeira avaliação estatística abrangeu apenas os resultados de laboratórios que utilizaram as técnicas de ICP-OES e AA, por representarem maior número de laboratórios participantes. A avaliação seguinte considerou todos os resultados, independente da técnica analítica empregada.

A Tabela 1 mostra os resultados obtidos para a determinação do elemento Fe por 11 laboratórios, que utilizaram as técnicas de ICPOES e AA. Na 1 ${ }^{\text {a }}$ rodada, cada laboratório adotou as condições operacionais estabelecidas para seu instrumento em sua rotina. A posição de cada um dos laboratórios na elipse de confiança a $95 \%$ pode ser observada na Figura 6. A média para a amostra A foi de $0,288 \%$ Fe com desvio padrão de $0,033 \%$; para a amostra $\mathrm{B}$, a média foi de 0,293\% Fe e desvio padrão 0,037\%. Nenhum laboratório posicionou-se fora da elipse traçada. Os resultados de Fe, que se mantêm mais afastados dos demais do conjunto de laboratórios participantes, correspondem aos dos laboratórios 10 e 13 (Tabela 1) com valores de 0,350 e $0,220 \%$ (para a amostra A) e de 0,360 e $0,230 \%$ (para a amostra B).

A Figura 7 mostra o comportamento dos mesmos 11 laboratórios, quando avaliados estatisticamente pela técnica do z-score robusto.

Observa-se que os resultados dos mesmos laboratórios, 10 e 13, também são indicados como os mais dispersos, ou seja, com $|z|>3$.

Tabela 1. Resultados para o elemento $\mathrm{Fe}-1^{\mathrm{a}}$ rodada (11 laboratórios, técnicas utilizadas: ICP-OES e AA)

\begin{tabular}{|c|c|c|c|c|c|c|c|}
\hline \multirow[t]{2}{*}{ Laboratório } & \multicolumn{3}{|c|}{ Amostra A $(\% \mathrm{Fe})$} & \multicolumn{3}{|c|}{ Amostra B $(\% \mathrm{Fe})$} & \multirow[t]{2}{*}{ Técnica } \\
\hline & Rep 1 & Rep 2 & Média & Rep 1 & Rep 2 & Média & \\
\hline 3 & 0,284 & 0,289 & 0,287 & 0,318 & 0,319 & 0,319 & ICP \\
\hline 4 & 0,290 & 0,300 & 0,295 & 0,260 & 0,260 & 0,260 & AA \\
\hline 5 & 0,270 & 0,260 & 0,265 & 0,260 & 0,250 & 0,255 & AA \\
\hline 6 & 0,270 & 0,280 & 0,275 & 0,330 & 0,330 & 0,330 & $\mathrm{ICP}$ \\
\hline 7 & 0,310 & 0,300 & 0,305 & 0,290 & 0,300 & 0,295 & $\mathrm{ICP}$ \\
\hline 8 & 0,307 & 0,304 & 0,306 & 0,278 & 0,281 & 0,280 & AA \\
\hline 10 & 0,350 & 0,350 & 0,350 & 0,360 & 0,360 & 0,360 & AA \\
\hline 11 & 0,320 & 0,310 & 0,315 & 0,310 & 0,310 & 0,310 & AA \\
\hline 12 & 0,270 & 0,270 & 0,270 & 0,280 & 0,280 & 0,280 & $\mathrm{ICP}$ \\
\hline 13 & 0,220 & 0,220 & 0,220 & 0,230 & 0,230 & 0,230 & $\mathrm{ICP}$ \\
\hline 14 & 0,280 & 0,280 & 0,280 & 0,300 & 0,300 & 0,300 & ICP \\
\hline
\end{tabular}




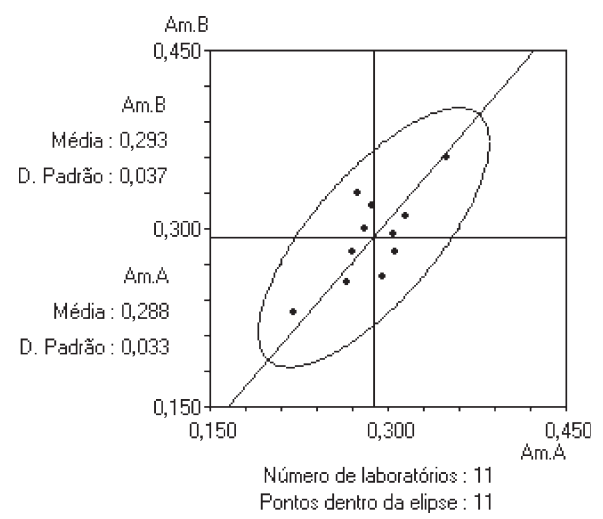

Figura 6. Elipse de confiança (95\%) para o elemento Fe (em \%). 1 a rodada (técnicas ICP-OES e AA)

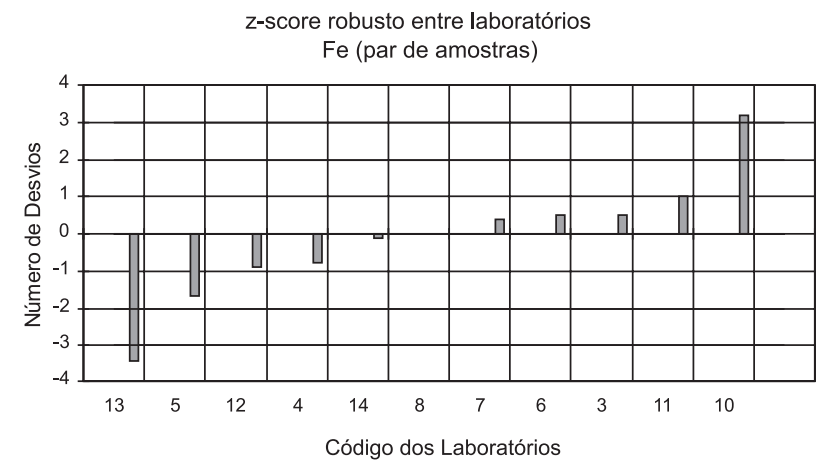

Figura 7. Gráfico do z-score robusto para o elemento Fe (em \%). $1^{a}$ rodada (técnicas ICP-OES e AA)

Aplicados os testes de Cochran e Grubbs, quando foram admitidos os resultados de todos os laboratórios participantes, foram calculados os índices $\mathrm{r}$ e $\mathrm{R}$, respectivamente, com valores de $0,01 \mathrm{e}$ 0,09 para a amostra A e 0,01 e 0,10 para a amostra B. Pode-se comentar que os laboratórios apresentaram uma boa repetitividade para a determinação do $\mathrm{Fe}$ em ambas as amostras. Os valores de R, para ambas as amostras, indicam que existem variabilidades entre os resultados dos vários laboratórios. Estas variabilidades podem ser diminuídas à medida que se identificam os principais fatores que influenciam nesses valores.

Os resultados para o elemento Ca estão mostrados na Tabela 2 e Figuras 8 e 9 .

Para a avaliação de $\mathrm{Ca}$, é observado que os valores correspondentes ao laboratório $7(0,028 \%$ Ca para a amostra A e $0,031 \% \mathrm{Ca}$ para a amostra B) e ao laboratório 13 (com 0,040\% Ca, a amostra A

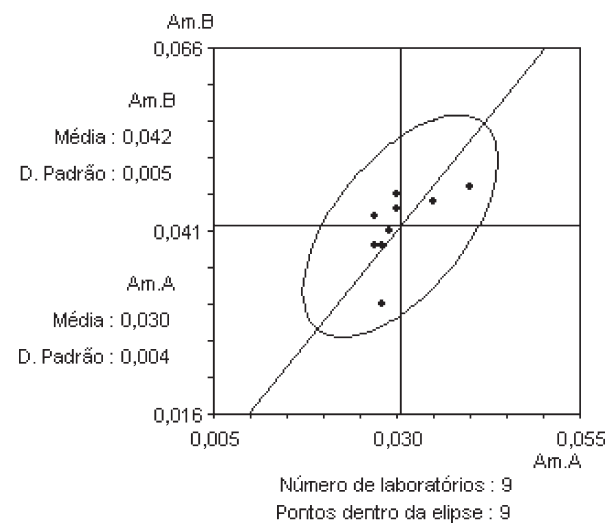

Figura 8. Elipse de Confiança (95\%) para o elemento Ca (em \%). $1^{\underline{a}}$ rodada (técnicas ICP-OES e AA)

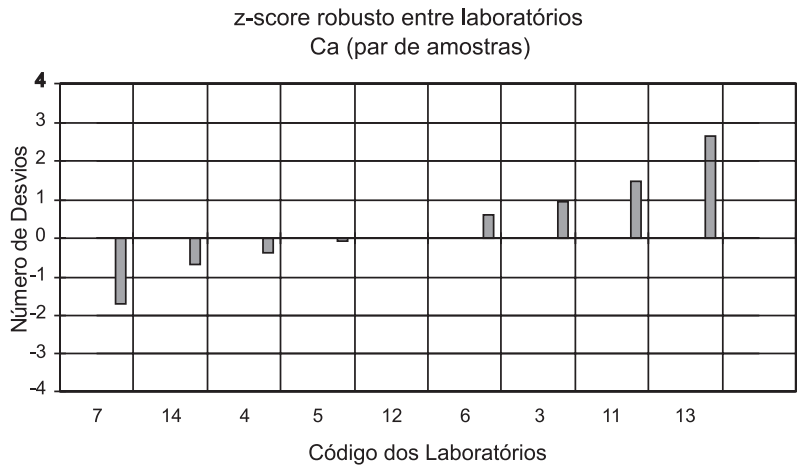

Figura 9. Gráfico do z-score robusto para o elemento Ca (em \%). Ia rodada (técnicas ICP-OES e AA)

e $0,047 \%$ Ca, a amostra B) representam pontos que estão mais distanciados dos demais na elipse traçada. $\mathrm{O}$ mesmo é indicado no gráfico do z-score robusto (Figura 9).

Os índices de $\mathrm{r}$ e R calculados para a amostra A na determinação de cálcio foram 0,005 e 0,013, respectivamente. Para a amostra B, foram $r=0,004$ e $R=0,014$. Resultados dentre laboratórios apresentam uma boa precisão, porém existem, como no caso da determinação de ferro, variabilidades entre os vários laboratórios, que podem ser identificadas e diminuídas.

Os resultados para a determinação de Ti, da $1^{\text {a }}$ rodada, estão apresentados na Tabela 3 e Figuras 10 e 11. Todos os resultados encontram-se dentro da elipse de confiança traçada. Verifica-se o mesmo comportamento dos laboratórios com o gráfico do z-score robusto. Após a aceitação dos resultados pelos testes de Cochran e Grubbs, que não excluem nenhum deles, os índices $r=9,0$ e $R=34,7$ calcula-

Tabela 2. Resultados para o elemento $\mathrm{Ca}-1^{\text {a }}$ rodada (9 laboratórios, técnicas utilizadas: ICP-OES e AA)

\begin{tabular}{cccccccc}
\hline Laboratório & \multicolumn{3}{c}{$\begin{array}{c}\text { Amostra A (\%Ca) } \\
\text { Rep 2 }\end{array}$} & Média & Rep 1 & Amostra B(\%Ca) & \multicolumn{2}{c}{ Técnica } \\
& Rep 1 & 0,030 & 0,030 & 0,046 & 0,045 & 0,046 & ICP \\
\hline 3 & 0,030 & 0,028 & 0,028 & 0,039 & 0,039 & 0,039 & AA \\
4 & 0,028 & 0,030 & 0,029 & 0,038 & 0,043 & 0,041 & AA \\
5 & 0,027 & 0,031 & 0,030 & 0,045 & 0,043 & 0,044 & ICP \\
6 & 0,028 & 0,028 & 0,028 & 0,030 & 0,031 & 0,031 & ICP \\
7 & 0,028 & 0,036 & 0,035 & 0,044 & 0,045 & 0,045 & AA \\
11 & 0,033 & 0,026 & 0,027 & 0,042 & 0,043 & 0,043 & ICP \\
12 & 0,028 & 0,042 & 0,040 & 0,046 & 0,047 & 0,047 & ICP \\
13 & 0,038 & 0,026 & 0,027 & 0,039 & 0,038 & 0,039 & ICP \\
\hline
\end{tabular}


Tabela 3. Resultados para o elemento $\mathrm{Ti}-1^{\mathrm{a}}$ rodada (7 laboratórios, técnicas utilizadas: ICP-OES e AA)

\begin{tabular}{|c|c|c|c|c|c|c|c|}
\hline \multirow[t]{2}{*}{ Laboratório } & \multicolumn{3}{|c|}{ Amostra A (mg/kg Ti) } & \multicolumn{3}{|c|}{ Amostra B (mg/kg Ti) } & \multirow[t]{2}{*}{ Técnica } \\
\hline & Rep 1 & Rep 2 & Média & Rep 1 & Rep 2 & Média & \\
\hline 3 & 80 & 79 & 79,5 & 78 & 72 & 75,0 & ICP \\
\hline 5 & 64 & 63 & 63,5 & 48 & 47 & 47,5 & AA \\
\hline 6 & 80 & 79 & 79,5 & 78 & 80 & 79,0 & ICP \\
\hline 7 & 70 & 78 & 74,0 & 60 & 64 & 62,0 & ICP \\
\hline 12 & 64 & 62 & 63,0 & 55 & 54 & 54,5 & $\mathrm{ICP}$ \\
\hline 13 & 62 & 67 & 64,5 & 53 & 55 & 54,0 & $\mathrm{ICP}$ \\
\hline 14 & 67 & 68 & 67,5 & 61 & 61 & 61,0 & $\mathrm{ICP}$ \\
\hline
\end{tabular}

dos para o elemento Ti, são considerados altos. Acredita-se que a grande dispersão dos resultados entre laboratórios e o baixo número de laboratórios participantes, nesse caso 7, resultou na aceitação dos laboratórios pelos testes de Cochran e Grubbs.

Utilizando o mesmo critério, foram avaliados os resultados obtidos para os demais elementos estudados, $\mathrm{Al}$ e Mn. Também nesses casos, a técnica do z-score robusto confirmou o posicionamento dos laboratórios quando seus resultados eram avaliados pela elipse de confiança.

Os resultados obtidos para os elementos $\mathrm{Al}$ e Mn foram também avaliados pela técnica da elipse de confiança e do z-score robusto, porém não estão ilustrados com figuras e gráficos nesse trabalho.

A Tabela 4 descreve os valores da média (X), do desvio padrão (s) e do coeficiente de variação (\%CV) para os elementos estudados, obtidos do conjunto de laboratórios.

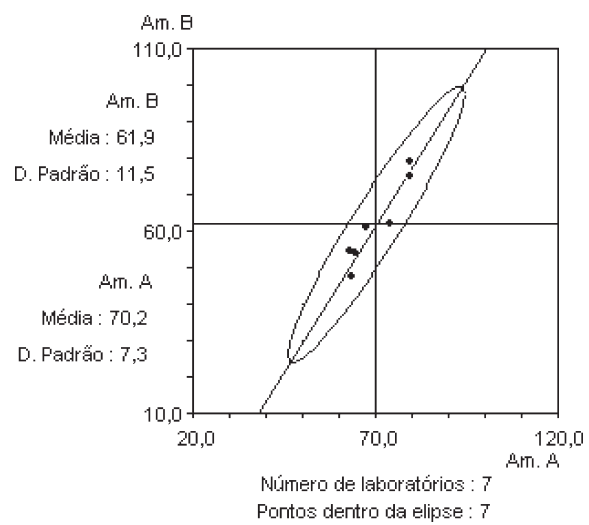

Figura 10. Elipse de confiança (95\%) para o elemento Ti (em $\mathrm{mg} / \mathrm{kg})$. $1^{\underline{a}}$ rodada (técnicas ICP-OES e AA)

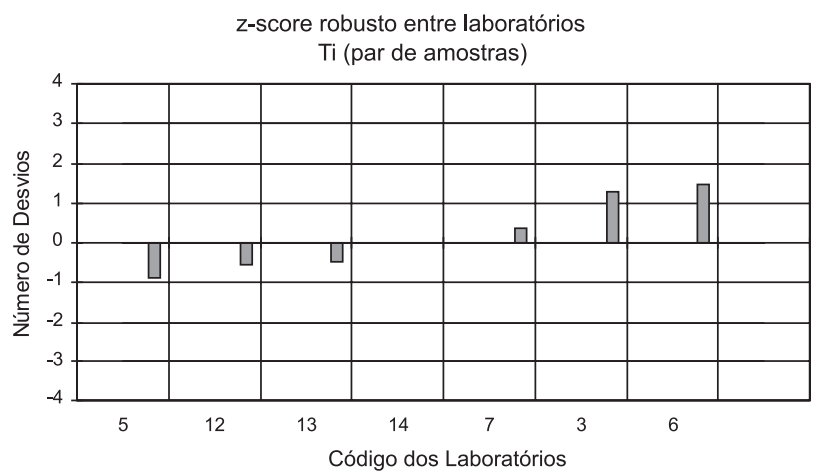

Figura 11. Gráfico do z-score robusto para o elemento $\mathrm{Ti}$ (em $\mathrm{mg} / \mathrm{kg}) .1^{\underline{a}}$ rodada (técnicas ICP-OES e AA)
Tabela 4. Média (X), Desvio Padrão (s) e Coeficiente de Variação $(\% \mathrm{CV})$ dos elementos determinados na $1 \stackrel{\text { a }}{\text { rodada }}$ (técnicas utilizadas: ICP-OES e AA)

\begin{tabular}{lcccccc}
\hline Elemento & \multicolumn{3}{c}{ Amostra A } & \multicolumn{3}{c}{ Amostra B } \\
& $\mathrm{X}$ & $\mathrm{s}$ & $\% \mathrm{CV}$ & $\mathrm{X}$ & $\mathrm{s}$ & $\% \mathrm{CV}$ \\
\hline $\mathrm{Fe}(\%)$ & 0,288 & 0,033 & 11,4 & 0,293 & 0,037 & 12,6 \\
$\mathrm{Ca}(\%)$ & 0,030 & 0,004 & 13,3 & 0,042 & 0,005 & 11,9 \\
$\mathrm{Al}(\%)$ & 0,061 & 0,008 & 13,1 & 0,066 & 0,008 & 12,1 \\
$\mathrm{Mn}(\mathrm{mg} / \mathrm{kg})$ & 75,8 & 6,8 & 9,0 & 104,1 & 11,7 & 11,2 \\
$\mathrm{Ti}(\mathrm{mg} / \mathrm{kg})$ & 70,2 & 7,3 & 10,4 & 61,9 & 11,5 & 18,6 \\
\hline
\end{tabular}

Mediante os resultados obtidos, observou-se que a dispersão era bastante elevada, com o coeficiente de variação de 9 a $13 \%$, exceto para o elemento $\mathrm{Ti}$, na amostra $\mathrm{B}$, que apresentou valor de $18,6 \%$.

A discussão dos resultados foi feita, em reunião, com a presença dos laboratórios participantes, enfocando os métodos de análise empregados, os procedimentos operacionais adotados e a rastreabilidade das medições obtidas.

Houve consenso quanto aos motivos pelos quais os resultados entre os vários laboratórios mostravam-se dispersos. Os diferentes procedimentos para a abertura de amostra, adotados pelos laboratórios, foram julgados como o principal fator que contribuía para a dispersão observada. Em consequiência, foi sugerido que todos os laboratórios repetissem a análise do material contido nos dois frascos recebidos, seguindo as sugestões levantadas em reunião para o procedimento de abertura de amostras e para as linhas de emissão, descritas a seguir.

Para a abertura de amostras de silício metálico em pó, foi sugerida a seguinte seqüência: (1) iniciar a análise com $1 \mathrm{~g}$ de amostra sólida; (2) adicionar $20 \mathrm{~mL}$ de $\mathrm{HNO}_{3}$ concentrado e $\mathrm{HF}$, gota a gota, até cerca de $10 \mathrm{~mL}$; (3) após digestão total da amostra, levar o material residual quase à secura; (4) retomar a amostra com $10 \mathrm{~mL}$ de $\mathrm{HCl}$ concentrado na proporção de 1:3; (5) transferir para balão volumétrico de $50 \mathrm{~mL}$ e completar o volume com água deionizada.

Os comprimentos de onda, em nm, para os elementos a serem determinados por ICP-OES e AA foram indicados: para Fe, 259,9 (ICP) e 248,3 (AA); para Ca, 317,9 (ICP) e 422,7 (AA); para Al, 396,1 ou 167,0 (ICP) e 309,3 (AA); para Mn, 257,6 (ICP) e 279,5 (AA) e para Ti, 334,9 (ICP).

Foi permitido, também, que os laboratórios utilizassem a técnica de FRX na nova rodada. Assim, a análise estatística dos resultados do 2o exercício de comparação interlaboratorial avaliou os resultados obtidos por ICP-OES, AA e FRX.

A Tabela 5 mostra os valores de média, desvio padrão e coeficiente de variação percentual para o novo conjunto de valores apresentados pelos laboratórios que utilizaram as técnicas ICP-OES e AA chama, após procederem à abertura das amostras. 
Tabela 5. Média (X), Desvio Padrão (s) e Coeficiente de Variação $(\% \mathrm{CV})$ dos elementos determinados na $2^{\underline{a}}$ rodada (técnicas utilizadas: ICP-OES e AA)

\begin{tabular}{lcccccc}
\hline Elemento & \multicolumn{3}{c}{ Amostra A } & \multicolumn{3}{c}{ Amostra B } \\
& $\mathrm{X}$ & $\mathrm{s}$ & $\% \mathrm{CV}$ & $\mathrm{X}$ & $\mathrm{s}$ & $\% \mathrm{CV}$ \\
\hline $\mathrm{Fe}(\%)$ & 0,298 & 0,028 & 9,4 & 0,304 & 0,025 & 8,2 \\
$\mathrm{Ca}(\%)$ & 0,031 & 0,004 & 12,9 & 0,042 & 0,005 & 11,9 \\
$\mathrm{Al}(\%)$ & 0,059 & 0,005 & 8,5 & 0,064 & 0,006 & 9,4 \\
$\mathrm{Mn}(\mathrm{mg} / \mathrm{kg})$ & 80,0 & 7,0 & 8,8 & 111,3 & 11,0 & 9,9 \\
$\mathrm{Ti}(\mathrm{mg} / \mathrm{kg})$ & 67,6 & 12,2 & 18,0 & 59,3 & 13,8 & 23,3 \\
\hline
\end{tabular}

Verificou-se que a precisão dos resultados obtidos pelos laboratórios que utilizaram técnicas para abertura de amostra foi maior, comparada à calculada na $1^{\mathrm{a}}$ rodada (Tabela 3 ), com exceção para Ti (18,0\% para a amostra A e $23,3 \%$, amostra B). Observou-se que a dispersão aumentou para os resultados de $\mathrm{Ti}$, fato que pode ser explicado pela baixa sensibilidade das técnicas ao elemento referido e problemas ainda existentes de solubilização de amostra para levar esse elemento em solução, mesmo com o procedimento para abertura de amostra proposto. Pode-se dizer que é necessário um esforço maior para diminuir as variabilidades na determinação de titânio em amostras de silício.

A Tabela 6 mostra os resultados para o elemento Fe (2 ${ }^{a}$ rodada) obtidos por 18 laboratórios participantes, alguns deles usando também a técnica de FRX. Os laboratórios de números 3, 12 e 17 participaram da comparação interlaboratorial utilizando duas técnicas diferentes, sendo designados como 3-A, 12-A e 17-A, como pode ser verificado nessa tabela.

A elipse de confiança traçada para o elemento $\mathrm{Fe}$, da $2^{\underline{a}}$ rodada, está mostrada na Figura 12 e o gráfico de z-score robusto, na Figura 13.

Para o elemento Fe, a elipse de confiança (Figura 12) indicou 2 laboratórios que se mostraram mais distantes dos demais: o de número 5 está representado pelo ponto no traçado da elipse e o de número 12-A, posicionado no quadrante inferior à esquerda. Ambos empregaram a técnica de absorção atômica. Esses mesmos laboratórios são os que mostram desvios maiores, quando se analisa o gráfico do z-score robusto (Figura 13). Quanto aos índices $r$ e R, foram

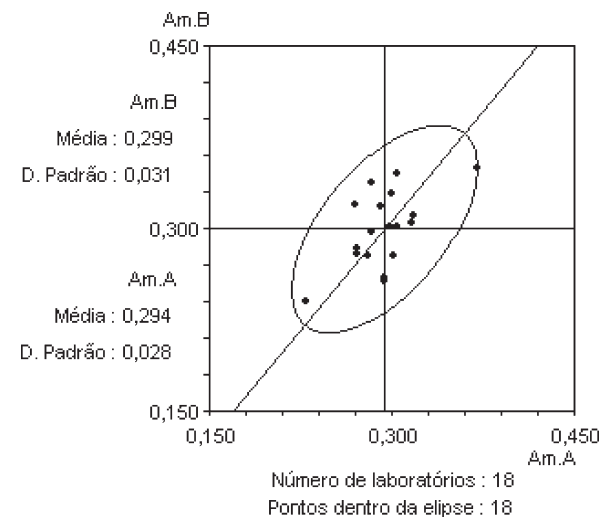

Figura 12. Elipse de confiança (95\%) para o elemento Fe (em \%). 2므 rodada (técnicas: ICP-OES, AA, FRX)

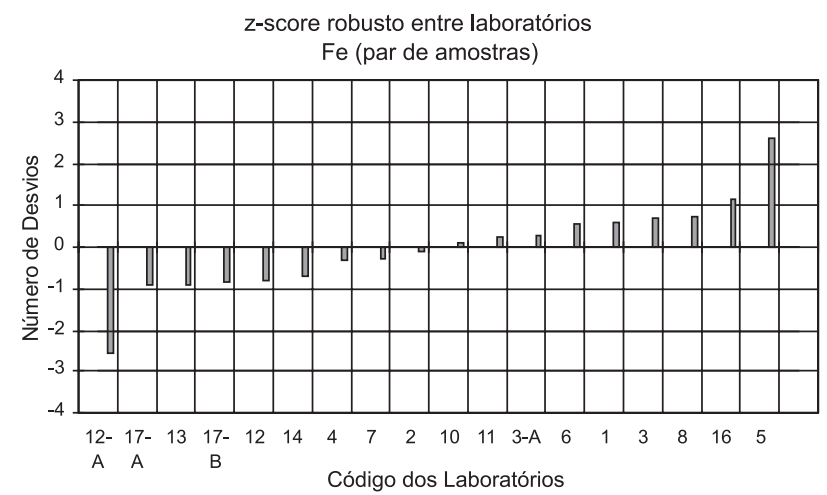

Figura 13. Gráfico do z-score robusto para o elemento $\mathrm{Fe}$ (em \%). $2^{\underline{a}}$ rodada (técnicas: ICP-OES, AA, FRX)

obtidos valores de 0,02 e 0,08, respectivamente, para a amostra A e 0,02 e 0,09 , respectivamente, para a amostra B. Observa-se que as variabilidades entre laboratórios diminuíram, para a determinação de ferro nessa rodada, quando se comparam com os valores de índice $\mathrm{R}(0,09$ para a amostra A e 0,10 , amostra B) da rodada anterior, embora os valores de $\mathrm{r}$, para ambas as amostras, fossem de 0,01 .

Tabela 6. Resultados para o elemento $\mathrm{Fe}-2^{\text {a }}$ rodada (18 laboratórios, técnicas utilizadas: ICP-OES, AA e FRX)

\begin{tabular}{|c|c|c|c|c|c|c|c|c|}
\hline \multirow[t]{2}{*}{ Lab } & \multicolumn{3}{|c|}{ Amostra A $(\% \mathrm{Fe})$} & \multicolumn{3}{|c|}{ Amostra B $(\% \mathrm{Fe})$} & \multirow[t]{2}{*}{ Técnica } & \multirow[t]{2}{*}{ Compr. de onda (nm) } \\
\hline & Rep 1 & Rep 2 & Média & Rep 1 & Rep 2 & Média & & \\
\hline 1 & 0,320 & 0,315 & 0,317 & 0,305 & 0,304 & 0,305 & FRX & \\
\hline 2 & 0,269 & 0,271 & 0,270 & 0,320 & 0,320 & 0,320 & FRX & \\
\hline 3 & 0,299 & 0,301 & 0,300 & 0,326 & 0,330 & 0,328 & ICP & 259,9 \\
\hline $3-\mathrm{A}$ & 0,294 & 0,287 & 0,291 & 0,315 & 0,320 & 0,318 & FRX & \\
\hline 4 & 0,300 & 0,304 & 0,302 & 0,270 & 0,285 & 0,278 & AA & 248,3 \\
\hline 5 & 0,390 & 0,350 & 0,370 & 0,340 & 0,360 & 0,350 & $\mathrm{AA}$ & 248,3 \\
\hline 6 & 0,283 & 0,284 & 0,283 & 0,342 & 0,334 & 0,338 & $\mathrm{AA}$ & 248,3 \\
\hline 7 & 0,284 & 0,283 & 0,283 & 0,296 & 0,298 & 0,297 & ICP & 259,9 \\
\hline 8 & 0,318 & 0,318 & 0,318 & 0,317 & 0,304 & 0,311 & ICP & 259,9 \\
\hline 10 & 0,307 & 0,288 & 0,298 & 0,302 & 0,299 & 0,301 & ICP & 259,9 \\
\hline 11 & 0,304 & 0,305 & 0,304 & 0,303 & 0,301 & 0,302 & $\mathrm{AA}$ & 248,3 \\
\hline 12 & 0,269 & 0,273 & 0,271 & 0,278 & 0,290 & 0,284 & ICP & 259,9 \\
\hline $12-\mathrm{A}$ & 0,230 & 0,231 & 0,230 & 0,237 & 0,243 & 0,240 & $\mathrm{AA}$ & 248,3 \\
\hline 13 & 0,270 & 0,274 & 0,272 & 0,280 & 0,278 & 0,279 & ICP & 259,9 \\
\hline 14 & 0,276 & 0,287 & 0,281 & 0,269 & 0,288 & 0,278 & ICP & 259,9 \\
\hline 16 & 0,300 & 0,310 & 0,305 & 0,350 & 0,340 & 0,345 & ICP & 238,2 \\
\hline $17-\mathrm{A}$ & 0,297 & 0,291 & 0,294 & 0,264 & 0,250 & 0,257 & $\mathrm{AA}$ & 248,3 \\
\hline 17-B & 0,302 & 0,287 & 0,294 & 0,264 & 0,255 & 0,259 & ICP & 259,9 \\
\hline
\end{tabular}


A determinação do elemento $\mathrm{Ca}$, na $2^{\mathrm{a}}$ rodada, tem seus resultados apresentados na Tabela 7 e Figuras 14 e 15. Todos os resultados encontram-se dentro da elipse construída com $95 \%$ de confiança e são confirmados com a avaliação gráfica do z-score robusto. Os testes de Cochran e Grubbs também aceitaram todos os resultados. Os índices r $(0,002)$ e R $(0,007)$ para a amostra A e r $(0,004)$ e R $(0,009)$ para a amostra $\mathrm{B}$ indicam uma precisão melhor, quando comparados com os valores de $\mathrm{r}(0,005)$ e $\mathrm{R}(0,013)$, para a amostra $\mathrm{A}$, e de $\mathrm{r}$ $(0,004)$ e de $\mathrm{R}(0,014)$, para a amostra $\mathrm{B}$, da $1^{\mathrm{a}}$ rodada. Isto mostra que melhorou a precisão dentre e entre laboratórios, como resultado

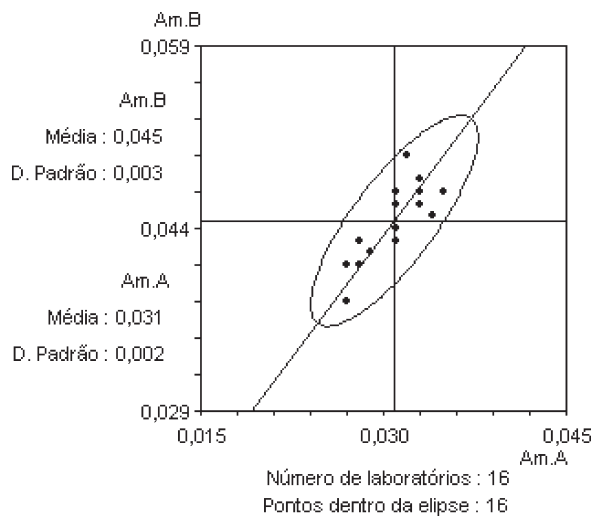

Figura 14. Elipse de confiança (95\%) para o elemento Ca (em \%). 2 ${ }^{a}$ rodada (técnicas: ICP-OES, AA, FRX)

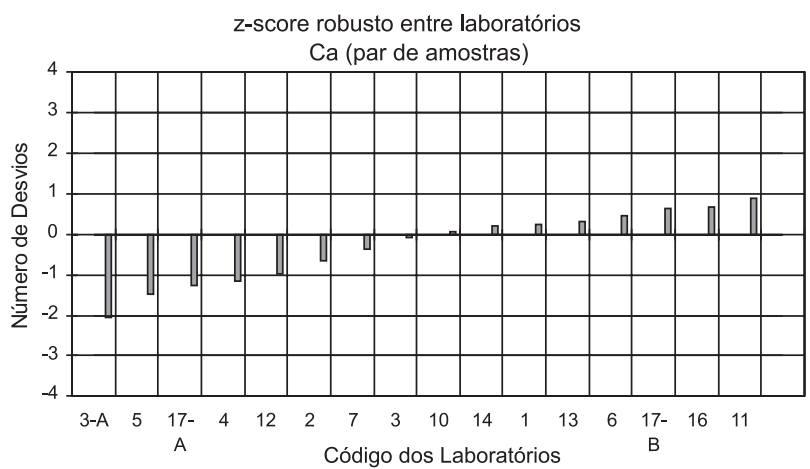

Figura 15. Gráfico do z-score robusto para o elemento Ca (em \%). $2^{a}$ rodada (técnicas: ICP-OES, AA, FRX) dos benefícios advindos das discussões promovidas em reuniões, em comparações interlaboratoriais.

Os resultados para o elemento Ti estão na Tabela 8 e Figuras 16 e 17. Para Ti, o valor obtido pelo laboratório 5 encontra-se fora da elipse de confiança (Figura 16), sendo seu distanciamento dos demais confirmado pelo gráfico do z-score robusto (Figura 17) com o número de desvio $|z|>3$. Os testes de Cochran e Grubbs também o indicaram como disperso dos demais. Os resultados do laboratório 5 não foram considerados nos cálculos dos índices $r$ e $R$. Os valores $r=5,3$ e $R=$ 15,2 indicam que existe uma grande dispersão entre os resultados dos

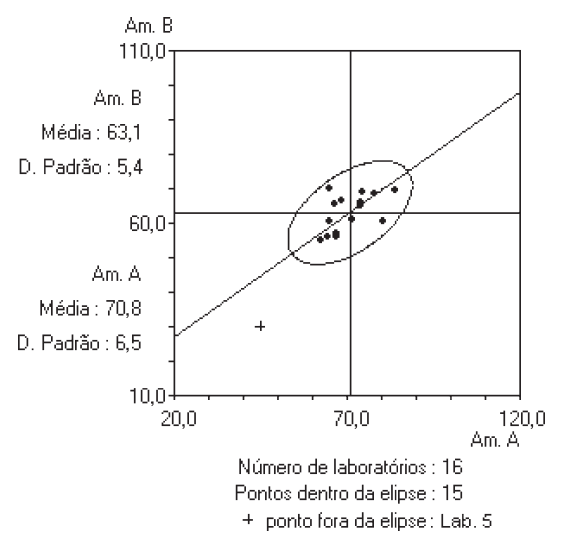

Figura 16. Elipse de confiança (95\%) para o elemento $\mathrm{Ti}$ (em $\mathrm{mg} / \mathrm{kg}) .2^{\underline{a}}$ rodada (técnicas $I C P$-OES, AA, FRX)

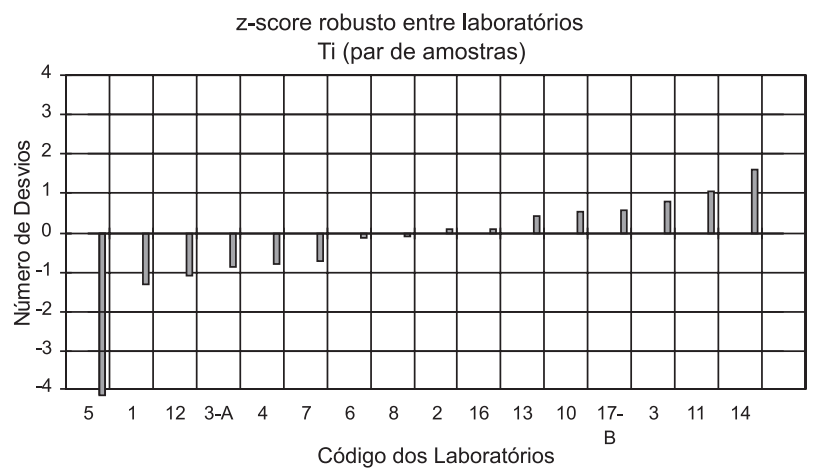

Figura 17. Gráfico do z-score robusto para o elemento $\mathrm{Ti}$ (em $\mathrm{mg} / \mathrm{kg}$ ). $2^{\underline{a}}$ rodada (técnicas: ICP-OES, $A A, F R X)$

Tabela 7. Resultados para o elemento $\mathrm{Ca}-2^{\mathrm{a}}$ rodada (16 laboratórios, técnicas utilizadas: ICP-OES, AA, FRX)

\begin{tabular}{|c|c|c|c|c|c|c|c|c|}
\hline \multirow[t]{2}{*}{$\mathrm{Lab}$} & \multicolumn{3}{|c|}{ Amostra A (\%Ca) } & \multicolumn{3}{|c|}{ Amostra B (\%Ca) } & \multirow[t]{2}{*}{ Técnica } & \multirow[t]{2}{*}{ Compr. de onda (nm) } \\
\hline & Rep 1 & Rep 2 & Média & Rep 1 & Rep 2 & Média & & \\
\hline 1 & 0,033 & 0,033 & 0,033 & 0,045 & 0,046 & 0,046 & FRX & \\
\hline 2 & 0,030 & 0,031 & 0,031 & 0,042 & 0,043 & 0,043 & FRX & \\
\hline 3 & 0,030 & 0,031 & 0,031 & 0,046 & 0,046 & 0,046 & $\mathrm{ICP}$ & 317,9 \\
\hline $3-A$ & 0,026 & 0,027 & 0,027 & 0,038 & 0,038 & 0,038 & FRX & \\
\hline 4 & 0,029 & 0,028 & 0,029 & 0,041 & 0,041 & 0,042 & $\mathrm{AA}$ & 422,7 \\
\hline 5 & 0,027 & 0,027 & 0,027 & 0,041 & 0,041 & 0,041 & AA & 422,7 \\
\hline 6 & 0,033 & 0,033 & 0,033 & 0,048 & 0,046 & 0,047 & $\mathrm{ICP}$ & 317,9 \\
\hline 7 & 0,031 & 0,030 & 0,031 & 0,044 & 0,045 & 0,044 & ICP & 317,9 \\
\hline 10 & 0,032 & 0,031 & 0,031 & 0,046 & 0,046 & 0,046 & ICP & 317,9 \\
\hline 11 & 0,035 & 0,035 & 0,035 & 0,047 & 0,048 & 0,047 & AA & 422,7 \\
\hline 12 & 0,028 & 0,028 & 0,028 & 0,043 & 0,043 & 0,043 & ICP & 317,9 \\
\hline 13 & 0,033 & 0,034 & 0,034 & 0,044 & 0,047 & 0,045 & $\mathrm{ICP}$ & 317,9 \\
\hline 14 & 0,031 & 0,031 & 0,031 & 0,047 & 0,047 & 0,047 & ICP & 317,9 \\
\hline 16 & 0,031 & 0,032 & 0,032 & 0,051 & 0,048 & 0,050 & $\mathrm{ICP}$ & 317,9 \\
\hline $17-\mathrm{A}$ & 0,029 & 0,028 & 0,028 & 0,040 & 0,042 & 0,041 & $\mathrm{AA}$ & 422,7 \\
\hline $17-\mathrm{B}$ & 0,032 & 0,034 & 0,033 & 0,045 & 0,050 & 0,048 & $\mathrm{ICP}$ & 317,9 \\
\hline
\end{tabular}


Tabela 8. Resultados para o elemento $\mathrm{Ti}-2^{\mathrm{a}}$ rodada (15 laboratórios, técnicas utilizadas: ICP-OES, AA e FRX)

\begin{tabular}{|c|c|c|c|c|c|c|c|c|}
\hline \multirow[t]{2}{*}{$\mathrm{Lab}$} & \multicolumn{3}{|c|}{ Amostra A (mg/kg Ti) } & \multicolumn{3}{|c|}{ Amostra B (mg/kg Ti) } & \multirow[t]{2}{*}{ Técnica } & \multirow[t]{2}{*}{ Compr.de onda(nm) } \\
\hline & Rep 1 & Rep 2 & Média & Rep 1 & Rep 2 & Média & & \\
\hline 1 & 62 & 63 & 62,5 & 54 & 56 & 55,0 & FRX & \\
\hline 2 & 69 & 68 & 68,5 & 66 & 67 & 66,5 & FRX & \\
\hline 3 & 73 & 76 & 74,5 & 67 & 71 & 69,0 & $\mathrm{ICP}$ & 334,9 \\
\hline $3-\mathrm{A}$ & 67 & 67 & 67,0 & 56 & 56 & 56,0 & FRX & \\
\hline 4 & 67 & 67 & 67,0 & 54 & 60 & 57,0 & UV & 410,0 \\
\hline 5 & 50 & 40 & 45,0 & 30 & 30 & 30,0 & AA & 364,3 \\
\hline 6 & 68 & 65 & 66,5 & 67 & 64 & 65,5 & ICP & 334,9 \\
\hline 7 & 64 & 66 & 65,0 & 61 & 60 & 60,5 & ICP & 334,9 \\
\hline 8 & 71 & 72 & 71,5 & 61 & 61 & 61,0 & ICP & 334,9 \\
\hline 10 & 73 & 75 & 74,0 & 65 & 67 & 66,0 & ICP & 334,9 \\
\hline 11 & 79 & 77 & 78,0 & 68 & 69 & 68,5 & UV & 420,0 \\
\hline 12 & 65 & 64 & 64,5 & 55 & 57 & 56,0 & ICP & 334,9 \\
\hline 13 & 74 & 74 & 74,0 & 66 & 64 & 65,0 & ICP & 334,9 \\
\hline 14 & 82 & 86 & 84,0 & 68 & 71 & 69,5 & ICP & 334,9 \\
\hline 16 & 60 & 70 & 65,0 & 70 & 70 & 70,0 & ICP & 337,3 \\
\hline $17-B$ & 78 & 83 & 80,5 & 59 & 62 & 60,5 & ICP & 334,9 \\
\hline
\end{tabular}

vários laboratórios e que é necessário continuar com os estudos para diminuir as variabilidades na determinação do elemento Ti.

Para os demais elementos, Mn e Al, cujas figuras não são ilustradas no presente trabalho, todos apresentaram valores bem distribuídos na elipse de confiança e confirmados pelo z-score robusto.

A Tabela 9 mostra todos os resultados, incluindo os obtidos com a técnica de FRX que prescinde da etapa de abertura de amostras.

Analisando-se os valores de coeficiente de variação, observa-se que, para todos os elementos, a dispersão dos resultados diminuiu.

Tabela 9. Média (X), Desvio Padrão (s) e Coeficiente de Variação $(\% \mathrm{CV})$ de elementos determinados na $2^{\mathrm{a}}$ rodada (técnicas utilizadas: ICP-OES, AA, FRX, UV)

\begin{tabular}{lcccccc}
\hline Elemento & \multicolumn{3}{c}{ Amostra A } & \multicolumn{3}{c}{ Amostra B } \\
& $\mathrm{X}$ & $\mathrm{s}$ & $\% \mathrm{CV}$ & $\mathrm{X}$ & $\mathrm{s}$ & $\% \mathrm{CV}$ \\
\hline $\mathrm{Fe}(\%)$ & 0,294 & 0,028 & 9,5 & 0,300 & 0,031 & 10,3 \\
$\mathrm{Ca}(\%)$ & 0,031 & 0,002 & 6,4 & 0,045 & 0,003 & 6,7 \\
$\mathrm{Al}(\%)$ & 0,060 & 0,005 & 8,3 & 0,064 & 0,006 & 9,4 \\
$\mathrm{Mn}(\mathrm{mg} / \mathrm{kg})$ & 80,5 & 6,0 & 7,4 & 110,9 & 8,8 & 7,9 \\
$\mathrm{Ti}(\mathrm{mg} / \mathrm{kg})$ & 70,8 & 6,5 & 9,2 & 63,1 & 5,4 & 8,6 \\
\hline
\end{tabular}

\section{CONCLUSÃO}

Através de programas interlaboratoriais, foi possível avaliar os resultados obtidos por vários laboratórios, que analisaram amostras de silício, utilizando técnicas analíticas diferentes.

Observou-se que o efeito devido a diferentes formas adotadas para a abertura de amostras, na análise química de silício metálico, foi o que mais influenciou na dispersão dos resultados entre diferentes laboratórios.

A utilização de diferentes linhas de emissão, quando se empregou a espectrometria de ICP-OES e AA, também representou fonte de variabilidade na determinação dos elementos presentes nas amostras analisadas.

Foi possível sugerir um procedimento para a abertura da amostra e a repetição dos trabalhos analíticos, com verificação do efeito devido a diferentes linhas de emissão a serem adotadas, principalmente referindo-se à aplicação da técnica da espectrometria de emissão por plasma.
Através da repetição dos trabalhos, seguindo as recomendações estabelecidas, a qualidade dos resultados obtidos pelos laboratórios melhorou (com exceção para Ti), podendo ser observada através da dispersão indicada. Em conseqüência, o novo coeficiente de variação dos valores resultantes resultou em valores menores, indicando que os exercícios de comparações interlaboratoriais podem ser bastante úteis como meios de auxiliar no aprimoramento dos trabalhos analíticos em laboratórios.

Os programas interlaboratoriais representam ferramentas úteis, subsidiando químicos analistas a melhorar a qualidade de suas medições. Usando softwares especialmente preparados é possível proporcionar resultados de avaliações com aspecto visual de fácil interpretação, auxiliando o laboratório participante a identificar seus problemas em métodos e procedimentos e a tomar as ações corretivas necessárias para melhorar seu resultado analítico.

As discussões em conjunto com os demais participantes representam uma oportunidade de troca de informações a respeito de técnicas e sua aplicação em matrizes não conhecidas. É possível diminuir as variabilidades intrínsecas de métodos e materiais, melhorando a qualidade dos resultados obtidos e gerando resultados metrologicamente confiáveis, principalmente quando não estão disponíveis outros meios de estabelecer a cadeia de rastreabilidade da medição desejada.

Participando de programas interlaboratoriais, os laboratórios podem identificar fontes de variabilidade e explicar eventuais discrepâncias de seus resultados, quando comparados aos dos demais laboratórios. Porém, é preciso salientar a importância da distribuição de amostras homogêneas aos laboratórios, papel atribuído ao coordenador ou aos provedores de programas interlaboratoriais.

Tendo em vista a busca pela melhoria contínua do laboratório, principalmente para aqueles engajados no atendimento aos requisitos da norma NBR ISO/IEC 17025 - Requisitos Gerais para a Competência de Laboratórios de Ensaio e Calibração ${ }^{28}$, os programas interlaboratoriais para averiguação de proficiência vêm apresentando um crescimento significativo. Outros benefícios podem ser citados: os programas interlaboratoriais fornecem subsídios ao laboratório participante para a manutenção do estado de calibração de seus equipamentos, uma vez que nem sempre é possível estipular as datas e estabelecer a frequiência para que estas operações sejam executadas; indicam situações em que o participante deve revisar seus pro- 
cedimentos; indicam a necessidade de investir na qualidade do trabalho do pessoal técnico e, por fim, facilitam o alcance de melhorias comerciais, uma vez que o risco de um desentendimento com clientes e usuários de serviços, devido a erros em ensaios, é minimizado. Para o desenvolvimento de materiais de referência, os programas interlaboratoriais tornam-se imprescindíveis, pois nem sempre existem métodos primários e laboratórios especializados para a certificação de materiais de referência com matrizes reais.

\section{AGRADECIMENTOS}

Aos laboratórios das empresas Ligas de Alumínio S/A (LIASA), Camargo Corrêa Metais S/A, Cia Ferroligas Minas Gerais (MINASLIGAS), SGS do Brasil, Sibra Eletrosiderúrgica, Carborundum do Brasil (Saint-Gobain Cerâmicas \& Plásticos Ltda), Electrometalurgica Andina (Argentina), Italmagnésio Nordeste S.A., Centros Tecnológicos da Marinha (Aramar e São Paulo), Fundação Centro Tecnológico de Minas Gerais, Instituto de Química da USP, IPEN/ CNEN/SP-Divisão de Radioquímica pela realização das análises químicas e à FAPESP pelo apoio financeiro (processo 00/06551-9)

\section{REFERÊNCIAS}

1. VIM - Vocabulário Internacional de termos fundamentais e gerais de metrologia; INMETRO/SENAI, 2 ed., Brasília, 2000.

2. ISO GUM - Guide to the Expression of Uncertainty in Measurement; $2^{\mathrm{a}}$ ed. brasileira (agosto de 1998) da 1a ed. revisada em inglês de 1995 (ISBN:92-67-10188-9); INMETRO/ABNT/SBM/RH Metrologia; Guia para expressão da incerteza de medição.

3. Valcárcel, M.; Principles of Analytical Chemistry - a Textbook, SpringerVerlag: Berlin Heidelberg, 2000, p. 256.

4. Bode, P.; Analyst 1995, 120, 1527.

5. Associação Brasileira de Normas Técnicas, ABNT/ISO/IEC Guia 43; Ensaios de proficiência por comparações interlaboratoriais. Parte 1: Desenvolvimento e operação de programas de ensaios de proficiência, Rio de Janeiro, Brasil, 1999.
6. Thompson, M.; Wood, R.; Pure Appl.Chem. 1994, 65, 2123.

7. Firth, J.; Protocol for the Contest Soils Analysis Proficiency Testing Scheme, $2^{\text {th }}$ ed., Lab. Govern. Chemist, Teddington: UK, 1996.

8. FAPAS-Protocol for the Food Analysis Performance Assessment Scheme; FAPAS Secretariat, CSL, Sand Hutton: York Y041 ILZ, UK, $5^{\text {th }}$ ed., 1997.

9. Chui, Q. S. H.; Sakuma, A. M.; Okada, I. A.; Maio, D. D.; Olivieri, J. C.; II Inter-American Congress on Metrology in Chemistry, São Paulo, Brasil, 2000.

10. International Organization for Standardization, ISO/DIS 5725; Accuracy (trueness and precision) of Measurement Methods and Results. Part 2: A basic method for the determination of repeatability and reproducibility of a standard measurement method, Geneva: Switzerland, 1990.

11. Royal Society of Chemistry/Analytical Methods Committee; Analyst 1989, 114, 19.

12. Thompson, M.; Anal. Chem. 1989, 61, 1942.

13. Rocke, D. M.; Biometrica 1983, 70, 421.

14. http:/www.nata.asn.au/fs_publication.htm, acessada em Outubro 2003.

15. Youden, W.J.; Industrial Quality Control 1959, 15, 1

16. Olivieri, J. C.; Publ. IPT 1759, 1988.

17. Mandel, J.; Lasshof, T. W.; J. Qual. Technol. 1987, 19, 29.

18. Jackson, J. E.; Industrial Quality Control 1956, $12,7$.

19. Nimeroff, I.; J. Opt. Soc. Am. B 1966, 56, 230.

20. Barros Neto, B. de; Scarmínio, I. S.; Bruns, R. E.; Planejamento e Otimização de Experimentos, 2aㅡ. ed., Ed. da UNICAMP, Campinas: São Paulo, 1996.

21. Box, G. E. P.; Hunter, W. G.; Hunter, J. S.; Statistics for Experimenters Introduction to Design, Data Analysis and Model Building, John Wiley \& Sons Ed.: New York, 1987.

22. International Organization for Standardization, ISO 35; Certification of reference materials - General and statistical principles, Geneva: Switzerland, 1985.

23. Chui, Q. S. H.; Antonoff, H. B.; Olivieri, J. C.; Quim. Nova 2002, 25, 657.

24. Kuselman, I.; J. Qual. Compar. Reliab. Chem. Meas. 1999, 4, 511.

25. Waeny, J. C. C; Publicação IPT 1156, 1985.

26. Waeny, J. C. C; ABCQ Nota Técnica 17/90 "Repetitividade e Reprodutividade III, São Paulo: Brasil, 1990.

27. http://www.lgc.co.uk/best/inhouse.pdf, acessada em Setembro 1999.

28. Associação Brasileira de Normas Técnicas, NBR ISO/IEC 17025; Requisitos gerais para competência de laboratórios de ensaios $e$ calibração, Rio de Janeiro: Brasil, 2001. 